paper, by Dr. M. Prestige and Dr. A. Hughes (Bristol), dealt with the possibility that lysosomes may play a part in cell degeneration in the central nervous system.

The very active discussion of the papers emphasized the present interest in the role of lysosomes in pathology as well as in normal physiology and embryology.

The third group was chaired by Prof. E. Wolff (Nogentsur-Marne); in the introduction to a discussion on interpretation of epigenetic malformations he pointed out that numerous physical or chemical factors, when applied at the same stage of development, produce the same types of malformations, such as cleft palates. On the contrary, other drugs have a specific teratogenic effect. The action of thalidomide on human foetuses has dramatically confirmed this point of view. The question arises of how these two different mechanisms can be explained.

Dr. W. Landauer (London) described his work on somo drugs such as insulin. Dr. J. Ebert and Dr. M. Reporter (Baltimore) reported their work on the action of actinomycin $A$ on differentiation of muscles in vivo and in vitro. This substance specifically inhibits the differentiation of the heart of the chick embryo in vivo and of muscle fibres in in vitro cultures. The authors extracted from the mito- chondrial fraction of tissues of the adult chick (liver and muscles) a protein that prevents the teratogenic effect of antimycin $A$. As a consequence this substance may be considered as inhibiting the formation of a protein essential in muscular differentiation.

Finally, Dr. Kirmann (Paris) showed that X-rays-a non-specific teratogenic factor-affect general respiratory metabolisms, which rosult in a decrease of oxygen consumption of the tissues. This metabolic effect as well as the teratogenic action of $\mathrm{X}$-irradiation can be prevented by anoxia or by substances-such as cysteamine--which are able to combino with free radicals arising in the tissues as a result of the ionization of water. So we can assumes that the two different mechanisms of activity of teratogenic substances may be related to whether they affect general or specific motabolisms.

In addition some eighty demonstrations were presented by members of the conference, ranging over all branches of embryology. The conforence was made possible by the generosity of the International Union of Biological Sciences, the Royal Society and by a number of industrial organizations. The eighth International Embryological Conference will be hold in Berne, Switzerland, in 1967.

\title{
SEAWEED RESEARCH
}

$\mathrm{T}$ HE fifth International Seaweed Symposium was held at Dalhousie University in Halifax during August 25-28. The purpose of these conferences has been to foster original research, both fundamental and applied, in the field of marine algae and to facilitate the presenta. tion of such investigations. Previous symposia have been held at Edinburgh, Trondheim, Galway, and Biarritz, on a triennial cycle. In a programme of four invited lecture. and 55 original communications, the topics were evenly divided between botanical, chemical, and applied aspects. A symposium within a symposium developed on the subject. of algal polysaccharides.

In discussing the seaweed industry of the future, F. N. Woodward (Scotland) emphasized the possibilities of mass culture as a source of protein, the cultivation of areas for selected species as in Japan, the great need for mechanization in harvesting and drying, and the possibilities of further applications of the unique algal polysaccharides in agriculture, industry, and medicine. The use of mustard, Sinapis alba, as a test plant with which to assess growth response to seaweed extracts was described by Challen and Homingway (United Kingdom). Stephenson (United Kingdom) reported specific effects from the use of liquid seaweed fertilizer as contributing to enhanced resistance of some field crops to frost, to pathological fungi, as Botrytis on strawberries, and to animal parasites, such as aphids on beans and sugar beets.

In a masterly lecture on recent studies of the polysaccharides of Agarophytes, Araki (Japan) described his investigations of the chemical constitution of agaroso and agaropectin. Sulphate groups as half-esters were established in agaropectin only. The remarkable finding of variable but appreciable amounts (1-20 per cent) of 6-O-methyl-Dgalactose in agarose was reported. Pyruvic acid was confirmed as a constituent of only two agaropectins. In agarose the molar ratio of D-galactose $+6-O$-methyl-Dgalactose to 3,6 -anhydro-L-galactose was always unity.

Anderson and Rees (Scotland) have found that carrabiose units account for 88-99 per cent of the molecule of $x$ - and $\lambda$-carrageenens based on the products after methanolysis of native and alkali-treated matorial. A new, widoly distributed, sulphated heteroglycan, isolated first from Ascophyllum, has been discoverod by Larsen and Haug (Norway) and named aseophyllan. It contains fucoso, $\mathrm{x}$ ylose and a uronie acid. The uneven distribution of mannuronic and guluronic acids in the main chain of alginic acid was postulated by Haug and Larsen (Norway) from investigations of partial hydrolysis with oxalic acid. The isolation of specific $x$ - and $\lambda$-carragoenases from Pseudomonas carrageenovora was reported by Yaphe et al. (Canada).

The finding of pure poly- $N$-acetylglucosamine as the only constituent of the extracellular fibres of the diatom, Thalassiosira fluviatilis, by MeLachlan, MeInnes, Falk and Craigie (Canada) provides the only instance in Nature of the occurrence of this substance in pure form. It has been renamed chitan. Two other unusual compounds were reported as occurring in marino algae-dimethyl- $\beta$-propiothetin and 2,3-dibromobenzyl alcohol-4,5-disulphate.

Black et al. (Scotland) described a survey of many of the Rhodophyceae as possible sources of the carrageenans. Marked variations in yield, ratio, optical rotation, and chemical composition wore recorded. Sharp fractionation into $x$ - and $\lambda$-components with potassium chloride was not always achieved, for oxample, in Eucheuma spinosum and Polyides rotundus. Fleming, Hirst and Manners (Scotland) have found notable similarity in the soluble and insoluble forms of laminarin except that the former exhibits a greater degree of branching. Painter (Uniter Kingdom) presented evidence that the sulphate group in the galactose of $x$-carrageenan and furcellaran is more or less randomly distributed over all available hydroxyl groups in the carbohydrate chains and not only attacherl at C-4 as previously believed.

The unexpected property of some seaweeds to "fix" radioactive ions was described by Czapke (Poland) and Skoryna et al. (Canada). The present explanation is based on ion-exchange with soluble or insoluble alginate. This property was applied as an index of the radioactivityof the aqueous environment and as a means of inhibiting absorption of strontium-89 in the gastro-intestinal tract of animals.

In a woll-illustrated study of the lissues of Fucus, McCully (United States) pointed out differences between the walls of the outer epidermal cells with their amorphous outor layer, the underlying parenchyma and the contral medulla with its reticulum of branched primary filaments and secondary intrusive fibres, all these being embedded in a mucilaginous matrix. Observations with the light microscope, using specific stains and extended by oloctron 
microscopy of adjacent sections, suggest that fucoidin is confined almost entirely to the mucilaginous matrix, while cellulose and alginic acid are in well-defined bands in the fibrillar portions of all the walls. A similar topic was troated by Baardseth (Norway), who examined the localization and structure of alginate gels from Ascophyllum. He belioves that alginates exist mainly as intercellular substances at all stages of development, and he finds no evidence for two walls in brown algae, a primary wall of alginate and a secondary wall of cellulose.

Chapman (Now Zoaland) discussed the physiological ecology of seaweeds in a general lecturo. For a number of the macroscopic algae which are found on the coasts of Australia and New Zealand, Chapman showed how physical factors which affect thoir distribution can also effect morphological variations. Ho gave many exporimental data suggesting that changes in light, temperature, depth, desiccation, etc., could influence the ability of the algae concerned to function at their optimum and hence could be responsible for the limits of distribution.

Kain (United Kingdom) showed that the lower level of Laminaria hyperborea in the Isle of Man may be determined partly by biotic factors: removal of colonies of Echinus esculentus from the lower limits of beds of $L$. hyperborea and Saccorhiza polyschides has resulted in new algal growth over rocks at a level which remained bare when Echinus was present. Leighton, Jones and North (United States) have doveloped a method of treatmont with quicklime to control the infestation of beds of Macrocystis by such sea-urchins in the Pacific Ocean. Many phaeophycean genera are known to produce tannins, and Conover and Sieburth (United States) gave evidence to show that these metabolites may influence the ability of certain organisms to grow in confined bodies of water.

In a session on specialized botanical topies, Anderson and North (United States) described ways in which estimates of the extent of sporing in Macrocystis have been made in situ. For isolated plants, sporelings have been found up to $5 \mathrm{~m}$ away, which suggests that the spores sink relatively quickly and do not wash about in the sea for any great length of time. Conway (Scotland) described the extensive sporing of species of Porphyra and the microseopic perennating phases into which the spores develop. Such phases may be of considerable ecological importance to this widely distributed genus. Aziz (Pakistan) reported, for the first time, sexual reproduction in Acrochaetium liagorae Börg.

In one of two sessions devoted to the algal flora of the Antarctic, Lamb (United States) described the pattern of distribution seen in tho supra-littoral, littoral and infralittoral zones at the Argentine base at Melchior. Early in the southern summer almost no vegotation is visible on the littoral rocks. Once colonization begins in the gullies, development is very rapid and sproads across the zone. Examination of the infra-littoral by SCUBA diving showed marked zonation with some of the major algae, including Desmarestia, down to $30 \mathrm{~m}$. Zanoveld (United States) described surveys carried out along the coasts of Ross Island and Victorialand, Antaretica, often through enlarged seal holes. These showed that large algal beds were present at depths botween 6 and $35 \mathrm{~m}$, with red algae, such as Phyllophora antarctica, Iridaea obovata and Phycodrys quercifolia, as the dominant species. Light measuroments emphasizod the paucity of light in such a habitat (about $1 \cdot 1$ per cent of the surfaco values) and showed that benthic algae are capable of photosynthetic production under fast ice with a coverage of 9-10 months.

Friedmann (Israel) described the occurrence in Mediterranean waters of numerous gametophytes of Padina pavonica and of the Indo-Pacific species P. gymnospora. Much variation in the occurrenco of bisexual and unisexual forms is found and there are indications that the variation in different populations is controlled by ecological factors. Moss (United Kingdom) reported experimental work which indicates the importance of the large apical cell in Fucus vesiculosus. Round (United Kingdom) has observed rhythms in migration of Euglena obtusa and of certain diatoms and the effect of varying the normal daylength pattern.

Most of the papers presented will appear in the official proceedings to be published as a separate volume by the Pergamon Press of London in 1966. There were 220 at the symposium who registered from 25 difforont countries. During the symposium a meeting of the International Phycological Society was held. The sixth symposium will be held in Spain in 1968, according to present plans. A permanent secretariat for the symposia has been set up in charge of Mr. E. Booth, Institute of Seaweed Research, Inveresk, Midlothian, Scotland. E. ConWaY

E. G. Yount

\title{
A SUGGESTED PHENOTYPIC CLASSIFICATION AND TERMINOLOGY FOR ENZYME MUTANTS IN MICRO-ORGANISMS
}

\author{
By Dr. J. F. COLlins*, Dr. J. MANDElSTAM, Prof. M. R. POLLOCK, F.R.S.*, Dr. M. H. RICHMOND* \\ and DR. P. H. A. SNEATH† \\ National Institute for Medical Research, Mill Hill, London
}

\begin{abstract}
$\mathrm{T}$ HERE is now a large and increasing number of different types of enzyme mutant being isolated among micro-organisms. The very wide range of activity levels and degrees of induction manifested emphasizes the need for some general phenotypic class'fication, based on onzymatic function, for indicating their physiological properties.

A convenient scheme can be obtained by classifying strains both aecording to thoir induetion response and according to tho maximum level of enzymatic activity expressed (Table 1). It is suggested here that four grades of performance with respect to each of these two independently variable functions (giving sixteen different * Present address: Department of Molecular Biology, University of Edinburgh.

+Present address: Medical Research Council Microbial Systematic Research Unit, University of Ieicester.
\end{abstract}

phenotypes) would, in this respect, cover the essontial properties of most strains ever likely to be recognized. In this schemo, the various categories are classified, purely on the basis of their phonotypic characters, by reference to the basal and maximally induced enzymo activities of the parent wild-type strain of micro-organism. 'Non-inducible' thus corresponds to 'constitutive' in the sense originally used by Karström ${ }^{1}$; the definition deponds, therefore, on absence of induction response and not on level of enzyme activity.

Certain adjustments and additions to the symmetrical scheme that emerges from the foregoing considerations have inevitably arisen. It is searcely practicable, for example, to abandon the term 'constitutive', which is well-established, and replace it by 'non-inducible'. But it is reasonable to suggest that it be used in its original 